\title{
INOVASI LAYANAN MPOSPAY DAN FREE PICK UP POS INDONESIA DALAM PENINGKATAN KUALITAS PELAYANAN
}

(Studi Pada Kantor Pos Semarang 50000)

\author{
Hardi Warsono \\ Administrasi Publik, FISIP, Universitas Diponegoro, hardie_wsn@live.undip.ac.id
}

Desti Relinda Qurniawati, Herta Sitorus, Soni Mukhammad Fajar S.

Administrasi Publik, FISIP, Universitas Diponegoro, infomia@undip.ac.id

\begin{abstract}
Abstrak
Pelayanan publik yang tidak bersifat monoplistik harus melakukan inovasi layanan secara terus menerus agar tetap bisa bersaing dengan kompetitor dan dapat memuaskan pelanggannya. PT Pos Indonesia sebagai salah satu BUMN di Indonesia juga dihadapkan pada tuntutan melakukan inovasi agar tidak kalah dengan pesaing swasta. PT Pos merupakan salah satu BUMN yang memberikan pelayanan ekspedisi pada masyarakat, diantara banyaknya pelayanan jasa serupa. Penelitian ini bertujuan untuk mengetahui inovasi layanan dan kualitas pelayaan di Kantor Pos Semarang 50000. Penelitian dilakukan dengan kualitatif. Teori utama untuk mengukur kualitas pelayanan didasarkan pendapat A Parasuraman yang mengukur kualitas pelayanan dari indikator: bukti fisik (tangibles), kehandalan (reliability), daya tanggap (responsiveness), jaminan (assurance) dan empati (empathy). Hasil penelitian menunjukkan bahwa inovasi-inovasi pelayanan di PT Pos Indonesia untuk peningkatan kualitas pelayanan sudah cukup baik, namun masih dijumpai beberapa kekurangan antara lain: penyampaian informasi inovasi baru dari petugas kepada pelanggan masih kurang efektif, sehingga inovasi ini terkesan dibuat tidak optimal. Pada umumnya kualitas layanan sudah baik, mulai dari respon petugas, fasilitas yang disediakan, jaminan dan pelayanan yang diberikan. Masih dijumpai kekurangan pada penyampaian informasi yang belum efektif kepada pelanggan. Penelitian ini merekomendasikan perlunya penyampaian informasi secara lugas dan detail mengenai inovasi yang dilakukan.
\end{abstract}

Kata Kunci : Inovasi, Kualitas, Pelayanan

\begin{abstract}
Non-monoplistic public services must continuously innovate services in order to remain competitive with its competitors and can satisfy its customers. PT Pos Indonesia as one of the state-owned enterprises in Indonesia is also faced with the demand to innovate so as not to lose with the private competitors. PT Pos is one of the BUMN that provide services expedition on the community, among the many services similar services. This study aims to determine the service innovation and quality of service at the Post Office Semarang 50000. Research conducted with qualitative. The main theory to measure the quality of service is based on the opinion of A Parasuraman that measures the quality of service from indicators: tangibles, reliability, responsiveness, assurance and empathy. The result of the research shows that service innovation at PT Pos Indonesia for the improvement of service quality is good enough, but there are some deficiencies such as: the delivery of new innovation information from the officer to the customer is still less effective, so this innovation seems not optimal. In general the quality of service is good, ranging from the response officers, facilities provided, guarantees and services provided. There are still shortcomings in the delivery of information that has not been effective to the customer. This study recommends the need for accurate and detailed information about the innovations made.
\end{abstract}

Keywords: Innovation, Quality, Service 


\section{PENDAHULUAN}

\section{Latar Belakang}

Salah satu fungsi utama pemerintah adalah fungsi pelayanan masyarakat (Public Service Function). Kehadiran birokrasi pemerintah mutlak diperlukan dalam penyelenggaraan pelayanan publik. Pemerintah memiliki kewajiban menyediakan barang dan jasa yang diperlukan oleh masyarakat luas, baik melalui birokrasinya maupun melalui Badan Usaha Milik Negara (BUMN).

Peran pemerintah melalui BUMN sesuai dengan amanat UUD 1945 pasal 33 Ayat 2 yang menyebutkan cabang-cabang produksi yang penting bagi negara dan menguasai hajat hidup orang banyak dikuasai oleh negara. Hal ini berarti penguasaan Negara atas cabangcabang produksi tersebut diwujudkan dalam bentuk perusahaan Negara (BUMN). Berdasarkan UndangUndang Nomor 9 Tahun 1969, BUMN adalah seluruh bentuk usaha negara yang modal seluruhnya atau sebagian dimiliki oleh negara/pemerintah dan dipisahkan dari kekayaan negara. Pengertian ini diperkuat dengan Undang-Undang Nomor 19 Tahun 2003 Tentang BUMN, yang dimaksud BUMN adalah badan usaha yang seluruh atau sebagian besar modalnya dimiliki oleh negara melalui penyertaan secara langsung yang berasal dari kekayaan negara yang dipisahkan.

Salah satu BUMN yang ada di Indonesia adalah Pos Indonesia. Pos Indonesia merupakan sebuah BUMN yang bergerak dibidang jasa pelayanan. Saat ini, bentuk badan usaha pos Indonesia merupakan perseroan terbatas dan sering disebut dengan PT. Pos Indonesia. Bentuk usaha pos Indonesia terdapat dalam PP RI Nomor 5 Tahun 1995, peraturan pemerintah tersebut berisi tentang pengalihan bentuk awal pos Indonesia yang berupa perusahaan umum (perum) menjadi sebuah perusahaan milik pemerintah dengan status persero.

Berubahnya status Pos Indonesia ini menjadi PT (Perseroan Terbatas), maka PT Pos Indonesia wajib mencari keuntungan sebanyak-banyaknya. Namun saat ini PT Pos Indonesia tidak sendirian. Perusahaan di luar pemerintah (swasta) yang bergerak di bidang jasa pelayanan pengiriman paket saat ini sudah banyak. Dahulu PT Pos selalu menjadi andalan utama dalam jasa pengiriman uang maupun barang. tapi saat ini PT Pos sudah mulai terpinggirkan oleh para kompetitor yang ternyata lebih disukai oleh masyarakat. PT Pos Indonesia memiliki cabang yang terletak di seluruh penjuru Indonesia, hal ini bisa saja menjadi keuntungan bagi PT Pos karena para pesaing lain belum memiliki cabang diseluruh pelosok Indonesia. Bahkan hal ini bisa dimanfaatkan oleh pemerintah untuk membuat programprogram pelayanan yang berhubungan langsung dengan masyarakat di daerah pelosok, yaitu program tentang ketersediaan informasi di daerah pelosok agar daerahdaerah yang jauh dari jangkauan informasi seperti akses internet dapat tersedia aksesnya dan kantor pos sebagai penghubung dari program tersebut. Tentu dengan keunggulan ini PT Pos seharusnya dapat menjadi pilihan utama. Kenyataannya saat ini PT Pos masih kalah bersaing dengan ekspedisi swasta yang lain. Berikut data tentang para pesaing PT Pos Indonesia.

Tabel 1

Top Brand Index Jasa Ekspedisi

\begin{tabular}{|c|c|c|c|}
\hline \multirow{2}{*}{ Merek } & $\mathbf{2 0 1 5}$ & $\mathbf{2 0 1 6}$ & $\mathbf{2 0 1 7}$ \\
\cline { 2 - 4 } & TBI & TBI & TBI \\
\hline JNE & $43,5 \%$ & $47,6 \%$ & $49,4 \%$ \\
\hline TIKI & $36,2 \%$ & $35,7 \%$ & $34,7 \%$ \\
\hline Pos Indonesia & $6,7 \%$ & $9,6 \%$ & $8,4 \%$ \\
\hline DHL & $2,1 \%$ & $1,3 \%$ & $1,3 \%$ \\
\hline
\end{tabular}

Sumber: Top Brand Index (www.topbrand-award.com)

Dari data tabel di atas, dapat dijelaskan bahwa PT. Pos Indonesia berada pada posisi ketiga Top Brand Index, posisi tersebut sangat jauh prosentasenya dengan ekspedisi yang lain, seperti JNE dan TIKI. Prosentase TBI Pos Indonesia mengalami penurunan pada tahun 2017 yakni sekitar 1,2\% dibanding tahun 2016, padahal pada tahun 2016 mengalami peningkatan yang cukup baik, yakni naik $2,6 \%$ dari tahun sebelumnya. Hal tersebut tidak sebanding jika melihat prosentase TBI JNE dan TIKI yang notabene adalah perusahaan swasta, berbeda dengan Pos Indonesia yang merupakan perusahaan BUMN. Sehingga hal ini diperlukan adanya inovasi yang dilakukan PT Pos Indonesia untuk dapat menyerap pangsa pasar lebih besar.

Semarang merupakan ibukota Propinsi Jawa Tengah yang memiliki tiga kantor utama dan memiliki fungsi berlainan. Pertama, Kantor Pos Besar Semarang 50000 terletak di Jalan Pemuda, merupakan kantor yang berhubungan langsung dengan pelanggan. Kedua, Kantor Wilayah Pos yang terletak di jalan Sisingamangaraja, berfungsi sebagai pusat kegiatan manajerial untuk wilayah Jawa Tengah dan DIY. Ketiga, Mail Processing Centre atau Sentral Pengolahan Pos terletak di Jl. Imam Barjo, Pleburan, Semarang 50241, merupakan kantor yang berfungsi sebagai tempat pengolahan semua kegiatan transaksi pengiriman yang dilakukan pada semua Kantor Pos yang ada di Semarang.

Dalam penelitian ini peneliti memilih lokasi kantor pos yang berhubungan langsung dengan pelanggan, yakni Kantor Pos Besar Semarang 50000. Kantor ini berorientasi untuk mendapatkan pelanggan sebanyakbanyaknya. Kantor Pos Besar Semarang 50000 pada akhir tahun 2017 melakukan inovasi layanan free pick up (layanan jemput kiriman gratis, pengantar pos yang 
mendatangi konsumen, satu pucuk surat tetap di jemput dan membantu mengepak barang kiriman konsumen).

Terdapat pula inovasi yang dilakukan oleh Kantor Pos Semarang 50000 yakni suatu layanan yang berbasis teknologi, pengguna layanan cukup melakukan transaksi melaui handphone berbasis android, layanan ini disebut dengan Mobile pos payment atau Mpospay, namun dari sisi pelayanan masih ada juga beberapa keluhan pelanggan mengenai layanan jasa Kantor Pos Semarang pada tahun 2014-2016 diantaranya sebagai berikut :

Tabel 2 Jenis Keluhan Pelanggan Tahun 2014-2017

\begin{tabular}{|c|c|c|}
\hline No & Jenis Keluhan & Prosentase \\
\hline 1 & $\begin{array}{c}\text { Surat / Paket tidak datang tepat } \\
\text { waktu (terlambat) }\end{array}$ & $97,75 \%$ \\
\hline 2 & Surat / Paket Rusak & $0,9 \%$ \\
\hline 3 & Surat / Paket Hilang & $1,4 \%$ \\
\hline
\end{tabular}

Sumber : Kantor Pos Semarang 50000 (olah data peneliti)

Dari tabel di atas dapat dilihat, bahwa jenis keluhan pelanggan tertinggi adalah surat/paket tidak datang tepat waktu. Hal tersebut menunjukkan layanan yang diberikan oleh kantor Pos Semarang 50000 belum dapat dikatakan optimal, karena masih tingginya angka keluhan pelanggan mengenai keterlambatan pengiriman surat maupun paket. Sedangkan untuk keluhan lainnya seperti barang hilang dan rusak memperoleh prosentase sebesar $1,4 \%$ dan $0,9 \%$.

Berdasarkan latar belakang tersebut, maka peneliti merasa perlu untuk membahas lebih lanjut tentang upaya Kantor Pos Semarang 50000 agar dapat bersaing dengan kompetitor yang menawarkan pelayanan dibidang yang sama. Peneliti tertarik melakukan penelitian dengan judul Inovasi Layanan Mpospay dan Free Pick Up Dalam Peningkatan Kualitas Pelayanan dan akan melakukan Studi Pada Kantor Pos Semarang 50000.

\section{Rumusan Masalah}

Berdasarkan uraian latar belakang dan identifikasi terhadap permasalahan inovasi layanan Mpospay dan Free Pick Up dalam peningkatan kualitas pelayanan di Kantor Pos Semarang 50000, maka dapat dirumuskan masalah penelitian sebagai berikut:

1. Bagaimanakah inovasi layanan Mpospay dan Free Pick Up di Kantor Pos Semarang 50000?

2. Bagaimana kualitas pelayanan yang diberikan oleh Kantor Pos Semarang 50000?

\section{Tujuan Penelitian}

1. Untuk mengetahui inovasi layanan Mpospay dan Free Pick Up di Kantor Pos Semarang 50000.

2. Untuk mengetahui kualitas pelayanan yang diberikan oleh Kantor Pos Semarang 50000.

\section{METODE}

Penelitian dilakukan dengan pendekatan kualitatif tipe deskriptif, jenis ini berupaya menggambarkan kejadian atau fenomena sesuai dengan apa yang terjadi dilapangan, data yang dihasilkan berupa kata-kata tertulis atau lisan dari orang-orang dan perilaku yang dapat diamati. Penelitian ini dilakukan di Kantor Pos Semarang 50000. Teknik yang digunakan dalam penentuan informan menggunakan purposive sampling. Teknik pengumpulan data dilakukan dengan wawancara, dokumentasi dan observasi.

\section{HASIL DAN PEMBAHASAN \\ Gambaran Umum Lokasi Penelitian}

PT Pos Besar Semarang 50000 beralamat di Jl. Pemuda No. 4, Pandansari, Kota Semarang, Jawa Tengah 50139, No. telepon 024-3543271, dengan kode kantor 50000 tipe B regional VI Semarang. Kantor Pos ini menaungi 34 kantor pos yang tersebar diwilayah Semarang. Kantor Pos ini merupakan kantor Pos besar yang berkewajiban untuk memeriksa ke 34 kantor pos di Semarang.

\section{Pembahasan}

\section{Inovasi Kantor Pos Semarang 50000}

\section{MPOSPAY}

Mpospay adalah layanan berbasis Mobile untuk produk kantorpos yang bisa diakses melalui smartphone oleh pelanggan, Mpospay merupakan singkatan dari Mobile Post Payment. Mpospay ini merupakan aplikasi yang dapat digunakan oleh pelanggan kantor pos untuk melakukan pembayaran melalui semua jenis rekening, baik itu pembayaran PLN, PDAM, Telkom, tagihan kartu prabayar, multifinance, tv kabel, asuransi BPJS dan terdapat juga fitur yang sifatnya umum yaitu seperti cek tarif, cari kode pos dan lacak kiriman. Mpospay dapat di download melalui link gg.gg//mpospay di Hp Android.

Untuk mengetahui lebih jauh mengenai layanan Mpospay, peneliti melakukan wawancara dengan manajer pelayanan kantor pos Semarang 50000, hasil wawancara menyebutkan bahwa pelayanan Mpospay merupakan salah satu inovasi baru yang dilakukan oleh Pos Indonesia, dalam pelayanan ini, data setiap konsumen atau pelanggan yang melakukan transaksi langsung masuk pada kantor pusat, layanan Mpospay juga dapat melakukan top up saldo pada akun pengguna, hal ini guna memudahkan pengguna layanan untuk melakukan transaksi. Berikut data transaksi yang dilakukan pada aplikasi Mpospay di Wilayah Semarang mulai dari april 2014 sampai januari 2018: 
Tabel 3 Transaksi Mpospay April 2014 Januari 2018

\begin{tabular}{|c|c|c|}
\hline Bulan & Tahun & Total Transaksi \\
\hline April-Desember & 2014 & 1 \\
\hline Januari-Desember & 2015 & 9 \\
\hline Januari-Desember & 2016 & - \\
\hline Januari-Desember & 2017 & 25 \\
\hline Januari & 2018 & 2 \\
\hline
\end{tabular}

Sumber: Pos Indonesia (olah data peneliti)

Tabel di atas dapat dijelaskan bahwa transaksi aplikasi Mpospay awal mula pengenalan inovasi pada April 2014 hanya terdapat 1 transaksi, dan terjadi peningkatan pada tahun 2015 sebanyak 9 transaksi, namun pada tahun 2016 justru tidak terdapat transaksi apapun, kemudian pada tahun 2017 terjadi peningkatan yang cukup signifikan, yakni sebanyak 25 transaksi, dengan adanya siklus turun naik jumlah transaksi pada layanan ini, membutuhkan peran petugas dalam penyampaian informasi mengenai transaksi baru tersebut, karena dari hasil wawancara yang peneliti lakukan dengan informan yaitu pelanggan kantor Pos Semarang 50000 , justru informan tidak mengetahui adanya aplikasi Mpospay, dalam hasil wawancara juga rata-rata pelanggan hanya memahami adanya aplikasi POS Indonesia yang bisa di download menggunakan play store.

2. Layanan Free Pick up

Layanan Free Pick Up merupakan salah satu inovasi terbaru yang dilakukan di kantor Pos Semarang 50000, layanan ini baru diresmikan pada tanggal 27 September 2017, di kantor Regional VI, jalan Sisingamaraja No. 45, Semarang dan sementara ini untuk wilayah Jateng-DIY terdapat di tiga Kota yaitu Semarang, Yogyakarta dan Kudus. Layanan free pick up tidak mengharuskan pelanggan untuk datang ke kantor pos jika ingin mengirim barang, hanya cukup melepon ke contact center 1500117.

Berikut data yang dapat peneliti peroleh dari kantor pos Semarang 50000, mengenai perbandingan sebelum adanya layanan free pick up dengan sesudah ada layanan tersebut, dapat dilihat dari tabel dibawah ini:

Tabel 4 Perbandingan sebelum dan sesudah ada layanan free pick up

\begin{tabular}{|c|c|}
\hline Bulan & Banyaknya Item \\
\hline Juni & 535 \\
\hline Juli & 2.946 \\
\hline Agustus & 7.707 \\
\hline
\end{tabular}

\begin{tabular}{|c|c|}
\hline September & 8.113 \\
\hline Oktober & 7.791 \\
\hline November & 9.799 \\
\hline Desember & 10.675 \\
\hline
\end{tabular}

Sumber: olah data peneliti

Tabel di atas dapat dijelaskan, bahwa ketika layanan free pick up ini dimulai pada bulan September 2017, terjadi penurunan pada bulan oktober hal ini dikarenakan, masih belum pahamnya pengguna layanan mengenai inovasi baru tersebut, namun dapat dilihat pada bulan November, dan Desember terjadi peningkatan yang cukup baik. Hasil wawancara yang peneliti lakukan dengan pelanggan kantor Pos Semarang 50000, mengenai layanan free pick up, informan menyampaikan bahwa inovasi terbaru yang dilakukan di kantor Pos Semarang sudah cukup bagus, karena dengan adanya layanan ini, pengguna layanan tidak perlu repot untuk datang ke kantor pos, sehingga waktu yang dibutuhkan tidak terlalu banyak bahkan dari beberapa informan yang lain menyampaikan, bahwa beliau sering menggunakan layanan free pick up.

\section{Kualitas Layanan Kantor Pos Semarang 50000}

Berdasarkan teori yang dikemukakan oleh Parasuraman (1990) dalam Arief (2007:135), terdiri dari 5 dimensi kualitas pelayanan publik yang yaitu Tangibles (Bukti Fisik), Reliability (Kehandalan), Responsiviness (Ketanggapan), Assurance (Jaminan), dan Empaty (Empati). Hasil dan analisis kualitatif terhadap masing-masing dimensi kualitas pelayanan dapat diuraikan dengan penjelasan sebagai berikut:

1. Dimensi Tangibles (Bukti Fisik)

Dimensi tangibles ditentukan oleh indikator yaitu penampilan aparatur saat memberikan pelayanan, fasilitas dalam memberikan pelayanan, penggunaan alat teknologi dalam pelayanan dan kedisiplinan petugas dalam melakukan pelayanan kepada para pelanggan. Kualitas pelayanan publik di Kantor Pos Semarang 50000 dalam dimensi tangibles berdasarkan hasil dari indikator-indikator yang digunakan dalam penelitian bisa dikatakan cukup baik karena dari indikator yang ada dalam hampir semuanya baik. Hanya saja terdapat satu poin indikator yang kurang baik, yakni mengenai teknologi, teknologi seyogyanya memang harus digunakan agar dapat mengimbangi perubahan zaman, namun terkadang yang menjadi kendala dalam perkembangan teknologi ini yakni internet, sehingga hal ini menyebabkan sedikit masalah 
pada saat melayani pelanggan. Hal positif dalam dimensi ini antara lain kerapian petugas Pos Semarang 50000, kemudahan proses pelayanan dan kedisplinan petugas.

2. Dimensi Reliability (Kehandalan)

Reliability merupakan kemampuan untuk memberikan pelayanan secara tepat, sesuai standar dan keahlian penggunaan alat bantu dalam pelayanan publik yang dilakukan oleh Kantor Pos Semarang 50000. Indikator dalam dimensi ini yakni kecermatan, dan ketepatan waktu pengiriman. Analisis yang dilakukan di kantor Pos Semarang 50000 kurang memuaskan. Karena indikator-indikator yang digunakan dalam penelitian salah satunya menunjukkan hasil yang kurang baik. Indikator pertama mengenai kecermatan petugas dalam memberikan pelayanan kepada pelanggan, sistem pelayanan di kantor Pos Semarang 50000 sudah cukup baik, yakni dengan menggunakan alat teknologi serta standar pelayanan Service Excellent, kemampuan dan keahlian petugas dalam mengoperasikan alat bantu pelayanan tidak diragukan lagi. Indikator kedua ketepatan waktu pengiriman menunjukan hasil yang kurang baik, masih terdapat complaint dari pelanggan mengenai keterlambatan proses pengiriman, sehingga membuat pelanggan kurang nyaman dengan proses tersebut, namun pihak pos juga tidak serta merta mengabaikan keluhan ini, pihak CS akan memberikan konfirmasi kepada pelanggan terhadap keterlambatan proses pengiriman oleh kurir, ketika masih banyaknya keluhan, ketidaksiapan SDM dalam proses pengiriman ini harus dibenahi lagi.

3. Dimensi Responsibility (Daya Tanggap)

Responsibility merupakan kesediaan dan kesadaran untuk merespon setiap pelanggan yang menginginkan pelayanan dengan cepat, tepat, cermat, dan merespon setiap keluhan yang disampaikan oleh pelanggan di Kantor Pos Semarang 50000. Petugas kantor Pos Semarang 50000 memberikan salam kepada pelanggan merupakan salah satu hal yang baik dalam sistem pelayanan publik. Kemampuan yang dimiliki oleh petugas khususnya yang berada didepan mempunyai kemampuan yang lebih dibanding petugas yang berada dibelakang layar kantor Pos Semarang 50000. Selain berpendidikan setiap petugas yang didepan haruslah melewati pelatihan dari kantor Pos Semarang 50000 yang bermateri Service Excellent, namun dari indikator penyampaian respon keluhan pelanggan kurang maksimal, hal ini terlihat dari ketidakpahaman pelanggan untuk memberikan saran dan pengaduan pelayanan kantor Pos Semarang 50000, yang notabene sudah disediakan yakni Pohon Randu (saran dan pengaduan), pelanggan yang sengaja kami wawancarai justru menganggap Pohon Randu tersebut merupakan hiasan yang sengaja dipajang di dalam Kantor Pos Semarang 50000. Sehingga hal ini menurut pendapat kami, masih kurangnya penyampaian informasi kepada pelanggan mengenai keberadaan Pohon Randu tersebut. Hasil analisis dari dimensi ini dapat dijelaskan sebagai berikut: responsibility yang diberikan di kantor Pos Semarang 50000 masih kurang baik, karena masih kurangnya penyampaian informasi secara jelas dan lugas oleh petugas Kantor Pos Semarang 50000 mengenai sarana kritikan yang dapat dilakukan oleh pelanggan, namun salah satu indikator yang lain sudah menunjukkan hal yang positif yakni respon petugas terhadap pelanggan di Kantor Pos Semarang 50000, petugas menyapa setiap pelanggan di kantor Pos Semarang 50000 dan tidak adanya penumpukan antrian pelanggan yang meminta pelayanan, dikarenakan sudah terdapat nomor antrian yang jelas.

4. Dimensi Assurance (Jaminan)

Assurance merupakan kemampuan aparatur dalam memberikan jaminan, jaminan dari segi ketepatan waktu, biaya, legalitas, serta kepastian biaya dalam proses pelayanan publik di kantor Pos Semarang 50000. Indikator dalam dimensi ini yakni kepastian biaya, dan jaminan legalitas di Kantor Pos Semarang 50000.

Assurance pelayanan Pos Semarang 50000 memberikan jaminan pada setiap pelanggan yang meminta pelayanan. Hal ini diwujudkan dalam bentuk paket-paket pilihan pengiriman yang dapat dipilih oleh pelanggan, misal Pos Express, Reguler, Pos Kilat Khusus, dalam pilihan paket ini terdapat harga yang berbeda. Selain itu juga tedapat jaminan ganti rugi 100 persen bagi setiap pelanggan, apabila barang yang dikirim hilang, dengan cara menyertai KTP pengirim, resi dan struk bukti pembayaran. Hasil analisis yang dilakukan pada indikator ini dijelaskan sebagai berikut; assurance di Kantor Pos Semarang 50000 sangat bagus. Indikator-indikator dalam dimensi ini hasilnya bersifat positif dan baik untuk para pelanggan. Pihak Pos Semarang 50000 memberikan jaminan yang pasti kepada 
para pelanggan yang menggunakan jasa pelayanan di Kantor Pos Semarang 50000.

5. Dimensi Emphaty (Empati)

Emphaty yaitu perhatian yang diberikan kepada pelanggan pelayanan publik di kantor Pos Semarang 50000. Indikator pada dimensi ini yakni yakni mendahulukan kepentingan pelanggan dan sikap pelayanan yang ramah, sopan, santun, tidak diskriminatif (membedabedakan).

Sikap petugas pelayanan yang ada didepan loket pelayanan pos Semarang 50000 juga baik. Petugas menyapa setiap pelanggan dan menerima para pelanggan dengan posisi berdiri. Hal itu juga telah diatur oleh Pos lewat Service Excellent yang diberikan ada setiap para petugas Pos. Indikator kedua yakni sikap petugas yang tidak diskriminatif. Sikap ini jarang sekali terjadi bahkan dapat dikatakan tidak mungkin, karena setiap pelanggan kantor Pos Semarang 50000 sudah mengambil nomor antrian masing-masing dan proses pemanggilannya pun secara bergilir, sesuai dengan nomor antrian sebelumnya.

Pembahasan mengenai dimensi-dimensi kualitas pelayanan menunjukan hasil yang cukup baik. Hampir dari semua dimensi ini di jalankan dengan profesional dan kompeten oleh petugas kantor Pos Semarang 50000. Hal yang menyebabkan baiknya dimensi ini antara lain adalah. Pertama, petugas yang kompetitif. Petugas yang melayani dengan ramah dan dapat menciptakan kesan pertama yang baik bagi para pelanggan, hal tersebut dapat membangun rasa kepercayaan antar pelanggan dengan kantor Pos, sehingga menjadi hal penting dalam sebuah pelayanan. Kedua, kredibilitas dalam setiap pelayanan, setiap pelayanan yang dilakukan di Kantor Pos Semarang 50000 disertai dengan bukti struk yang berisi tentang catatan transaksi yang dilakukan oleh pelanggan, dengan adanya struk tersebut, pelanggan diyakinkan bahwa mereka akan dapat melakukan klaim apabila suatu saat terjadi kegagalan dalam pelayanan, yang terakhir adalah keamanan dalam pelayanan. Kantor Pos Semarang 50000 mampu memberikan keamanan dalam setiap pelayanannya, yakni dengan adanya proses pencatatan yang dilakukan pihak pos untuk barang yang akan dikirim dan adanya kejelasan biaya yang harus dikeluarkan oleh pelanggan.

\section{PENUTUP}

\section{Simpulan}

Hasil penelitian dapat disimpulkan bahwa beberapa inovasi yakni inovasi Mpospay dan Free pick up yang dilakukan oleh Pos Semarang 50000 sudah baik dalam merespon persaingan saat ini, hanya saja pihak Pos belum konsisten dalam hal pengimplementasian inovasi tersebut. Masih ditemukan ketidakpahaman pelanggan mengenai inovasi baru yang dihadirkan. Disarankan penyamapaiain informasi inovasi dapat dilakukan dengan lugas dan konsisten agar pelanggan dapat merasakan manfaat inovasi yang dibuat.

Dari dimensi kualitas pelayanan yang digunakan untuk melihat dan mengukur kualitas pelayanan pada kantor Pos Semarang 50000 berupa Tangibles (Bukti Fisik), Reliability (Kehandalan), Responsiviness (Ketanggapan), Assurance (Jaminan), dan Empaty (Empati) didapatkan temuan:

1. Dimensi Tangibles sudah cukup baik, namun ada salah satu indikator yang kurang yakni kendala server error.

2. Dimensi Reliability : pada umumnya indikator yang digunakan dalam penelitian menunjukkan hasil yang cukup baik, namun demikian masih dijumpai kekurangan yakni indikator keluhan pada keterlambatan.

3. Dimensi Responsibility : terdapat dua indikator, satu indikator menunjukkan hasil yang baik dan satu indikator lainnya kurang baik. Kekurangan ini ditunjukkan oleh kurang efektifnya pemberian pemahaman petugas pada pelanggan, khususnya sarana dalam memberikan saran dan pengaduan terhadap pelayanan di kantor Pos Semarang 50000, bahkan beberapa pelanggan tidak memahami fungsi Pohon Randu.

4. Dimensi Assurance semua indikator yang digunakan memperlihatkan hasil yang baik yang ditunjukkan oleh setiap indikator memunculkan hal-hal yang positif. Baik dari segi jaminan tepat waktu dalam pelayanan, kepastian biaya dalam pelayanan serta jaminan legalitas dalam pelayanan.

5. Dimensi Emphaty memperlihatkan hasil yang baik, karena pelanggan merasa nyaman ketika diberi pelayanan oleh petugas.

\section{Saran}

Dari hasil penelitian dan kesimpulan yang ada, dengan melihat prospek pelayanan publik kedepan, maka peneliti dapat mengemukakan saran-saran sebagai berikut:

1. Petugas Kantor Pos Semarang 50000 seyogyanya lebih aktif dalam memberikan 
informasi kepada pelanggan terkait inovasi baru yang ada di kantor tersebut, misalnya informasi mengenai pemberian saran dan pengaduan (Pohon Randu)

2. Perlunya peningkatan promosi pada setiap inovasi baru yang dikeluarkan agar pelanggan mengetahui inovasi baru yang ada di kantor Pos Semarang 50000.

\section{DAFTAR PUSTAKA}

Arief. 2007. Pemasaran Jasa Kualitas Pelayanan. Banyumedia Publishing, Malang.

Arikunto, Suharsimi. 2006. Prosedur Penelitian: Suatu Pendekatan Praktik. Rineka Cipta, Jakarta.

Dwiyanto, Agus. 2008. Mewujudkan Good Governance Melalui Pelayanan Publik. Gajah Mada University Press. Yogyakarta.

Kusdi, 2011, Teori Organisasi Dan Administrasi. Salemba Humanika, Jakarta.

Kusmana, Suherli, 2010, Manajemen Inovasi Pendidikan. Pascasarjana Unigal Press. Ciamis.

Mahsun, Mohamad, 2006, Pengukuran Kinerja Sektor Publik, Penerbit BPFE,Yogyakarta,

Mardiasmo, 2004, Perpajakan. Penerbit Andi, Yogyakarta.

Moleong, Lexi J., 2006,Metodologi Penelitian Kualitatif. Remaja Posdakarya, Bandung.

Muluk. Khairul, 2008, Knowledge Management Kunci Sukses Inovasi Pemerintahan Daerah. Bayumedia Publising, Jatim.

Ndraha, Taliziduhu, 2005,Teori Budaya Organisasi. Rineka Cipta, Jakarta.

Nawawi, Hadari, dan Martini. 2006, Instrumen Penelitian Bidang Sosial. Gadjah Mada University Press. Yogyakarta.

Parasuraman, Valarie A Zeithaml, and Leonard L. Berry. 1988. "SERVQUAL: A Multiple-Item Scale for Measuring Consumer Perceptions of Service Quality”. Journal of Retailing. Vol 64 (1) pp 12-37

Sastrawidjaja, Man Suparman, Eksistensi BUMN Sebagai Perusahaan, Makalah dalam Seminar Nasional Implikasi Berlakunya Ketentuan Keuangan Negara Terhadap Pengelolaan Aset Badan Usaha Milik Negara (BUMN), Kelompok Studi Hukum Bisnis FHUNPAD, Jakarta, 5 Juli 2007.

Siagian, Sondang P., 2009, Kiat Meningkatkan Produktivitas Kerja. Penerbit Rineka Cipta, Jakarta.

Sugiyono. 2005, Memahami Penelitian Kualitatif. Alfabet, Bandung.
Suwarno, Yogi, 2005, Inovasi di Sektor Publik. STIALAN Press. Jakarta.

Sutrisno, Edy, 2010, Budaya Organisasi. Penerbit Kencana, Jakarta.

Suryani, Tatik, 2013, Perilaku Konsumen di Era Internet Implikasinya Pada Strategi Pemasaran. Penerbit Graha Ilmu, Yogyakarta.

Taufik, Tatang, 2005, Pengembangan Sistem Inovasi Daerah: Perspektif Kebijakan. Buana Press. Tangerang.

Tjandra, Elvi Anggraeni, 2008, Keberhasilan Inovasi Melalui Riset Dan Pengembangan Yang Tepat Akan Mempengaruhi Keberhasilan Produk Di Pasar, Vol. 01.

http://www.topbrand-award.com/top-brandsurvey/survey-result/top_brand_index_2017_fase_2 (15 Desember 2017)

http://www.topbrand-award.com/top-brandsurvey/survey-result/top_brand_index_2016_fase_2 (15 Desember 2017)

http://www.posindonesia.co.id/index.php/sejarah-pos/ (04 November 2017) 